\title{
A novel polyimide based micro heater with high temperature uniformity
}

\author{
Shifeng $\mathrm{Yu}^{1}$, Shuyu Wang ${ }^{2}$, Ming $\mathrm{Lu}^{3}$ and Lei Zuo ${ }^{1^{*}}$ \\ ${ }^{1}$ Department of Mechanical Engineering, Virginia Tech, Blacksburg, VA, 24061, USA \\ ${ }^{2}$ Department of Mechanical Engineering, Stony Brook University, Stony Brook, NY 11794, USA \\ ${ }^{3}$ Center for Functional Nanomaterials, Brookhaven National Laboratory, Upton, NY 11973, USA \\ *corresponding author: leizuo@ vt.edu
}




\section{Abstract}

MEMS based micro heaters are a key component in micro bio-calorimetry, nondispersive infrared gas sensors, semiconductor gas sensors and microfluidic actuators. A micro heater with a uniform temperature distribution in the heating area and short response time is desirable in ultrasensitive temperature-dependent measurements. In this paper we propose a novel micro heater design to reach a uniform temperature in a large heating area by optimizing the heating power density distribution in the heating area. A polyimide membrane is utilized as the substrate to reduce the thermal mass and heat loss which allows for fast thermal response as well as a simplified fabrication process. A gold and titanium heating element is fabricated on the flexible polyimide substrate using the standard MEMS technique. The temperature distribution in the heating area for a certain power input is measured by an IR camera, and is consistent with FEA simulation results. This design can achieve fast response and uniform temperature distribution, which is quite suitable for the programmable heating such as impulse and step driving.

Key words: micro heater, bio-calorimetry, temperature uniformity, polyimide membrane, fast response

\section{Introduction}

Micro heaters consists of a heating element and substrate, and have been applied widely for temperature control in MEMS sensors, especially in bio-calorimeters [1], gas sensors [2], microfluidic actuators [3] and IR applications [4]. There has a lot of work investigating different materials used as the heating source such as polysilicon [5], SiC [6], TiN [7], $\mathrm{Pt}$ [8], and $\mathrm{Au}$ [9]. When a voltage is applied to the terminals of the heater, which is often made of resistor materials, it will generate a certain amount of Joule heat. A thin film insulator such as $\mathrm{SiO}_{2}, \mathrm{Si}_{3} \mathrm{~N}_{4}$ or polymer membrane is usually used as the substrate for the heater. To reach high thermal insulation, the thin film substrate is usually suspended using several beams for support. Since MEMS fabrication is usually carried out on silicon wafers, which require a lot of etching work, it is time consuming and costly [10]. Thin films like $\mathrm{SiO}_{2}$ and $\mathrm{Si}_{3} \mathrm{~N}_{4}$ can only sustain small loads due to their poor mechanical strength, so the application of the heater based on these substrates is limited to some gas sensors and IR devices [11,12,13]. Recently however, polymer membranes, especially polyimide, have gained a lot of attention $[14,15]$ due to their robustness, low thermal conductivity, and simple fabrication process. In addition, the thermal expansion coefficient of polyimide membrane is quite close to that of a silicon wafer, which makes it quite comparable with the IC fabrication process. In fact, some companies such as Minco and Omega already have similar products by employing a meandering resistive track on polyimide to form a heating element.

Compared to the traditional hotplate, a MEMS based micro heater needs much lower driven power/voltage and costs much less. Due to the small size and simple structure, a micro heater is much faster in various types of thermal response. Recently, many papers reported their work in developing novel MEMS heaters which can achieve high heating temperatures and short response times $[4,5,7]$, however, while most of them mention the temperature distribution in the heating area, only a few works report about how to improve the temperature uniformity [16]. Good heating uniformity can increase the selectivity and sensitivity of the device which is potentially important in ultrasensitive NDIR gas sensing and micro calorimetry. For an NDIR gas sensor, the emissivity is both temperature and wavelength sensitive [17] while calorimetry measurements are directly temperature related [18]. Previous research results show that uniform heating power density will lead to non-uniform temperature distribution [19]. By thorough analysis of the heat transfer on the surface of the heater and carefully distributing the heating power, the heating area can reach high temperature uniformity.

In this paper we propose a novel micro heater on a polyimide membrane with high temperature uniformity and short thermal response time. A novel process is introduced to fabricate the flexible substrate using liquid polyimide. A gold resistor is utilized to release Joule heat. For the heater design, a numerical method is developed to analyze the relationship between the heating power distribution and the temperature uniformity. The optimization of temperature uniformity in the heating area is completed using an ANSYS thermal MEMS simulation. A prototype is then fabricated based on the simulation and tested. The measurement and simulation results are consistent. The time constant for the step response is also measured when $2 \mu \mathrm{L}$ water droplet is loaded on the substrate.

\section{Design and Fabrication}

\subsection{Temperature Distribution}

The micro heater is composed of a resistive $\mathrm{Au} / \mathrm{Ti}$ trace on a polyimide membrane. When a certain amount of heating power is applied to the heater, the temperature 
is quickly redistributed over the suspended polyimide membrane. The response time is on the milli-second scale due to the small thermal mass of the suspended polyimide membrane. The heat will ultimately be transferred through conduction to the periphery and convection with the air will occur along with some thermal radiation. When temperature in the heating area is less than $500 \mathrm{~K}$, the heat loss through radiation can be neglected compared to the total heating power supply [20]. Due to the low thermal conductivity of the polyimide membrane, the temperature attenuates rapidly in the non-heating area. When stable, most of the heat will be transferred to the air from the heating area through heat convection directly. Natural heat convection is caused by buoyancy forces due to the density difference caused by temperature variations in the air. When the sample area is heated, the fluid near the boundary is warmed, and becomes lighter. The buoyancy causes the fluid to rise and be replaced by a cooler fluid that will in turn be heated continuing the process [21]. When the polyimide based micro heater is placed horizontally, the coefficient of heat convection for the upper surface is different from that for the lower surface. The coefficient of heat convection depends on the gas which serves as the cooling fluid, the surface temperature of the sample and the geometrical configuration of the heater. The temperature distribution in the heating area is greatly affected by the contour of the heater and the distribution of the heating trace. The temperature distribution can be expressed by the Poisson equation [22] as follows:

$-\nabla(\mathrm{kt} \cdot \nabla \mathrm{T})=\sigma+\mathrm{h}\left(\mathrm{T}_{\mathrm{air}}-\mathrm{T}\right)$

$$
\begin{aligned}
\boldsymbol{h} & =\frac{0.54 \mathrm{kR}_{\mathrm{aL}}^{0} \cdot 25}{\mathrm{~L}}+\frac{0.27 \mathrm{kR}_{\mathrm{aL}}^{0} \cdot 25}{\mathrm{~L}} \\
& =\frac{0.81 k \mathrm{R}_{\mathrm{aL}}^{0} \cdot 25}{\mathrm{~L}} \\
\sigma & =\frac{\mathrm{dP}}{\mathrm{dS}}
\end{aligned}
$$

where: $\mathrm{k}$ is the thermal conductivity, and $\mathrm{t}$ is the thickness of the membrane, $\sigma$ is the heating power density in the heating area, $\boldsymbol{h}$ is the total coefficient of heat convection for the upward and downward surfaces, $\mathrm{L}$ is the characteristic length of the heater, specified by the area over the perimeter, $\mathrm{T}_{\text {air }}$ is the temperature of the air which is assumed constant, and $T$ is the local temperature in the membrane. Since the heater consists of a series of concentric gold traces, and the polyimide membrane is much larger than the heater itself, the temperature distribution in the plane of the membrane is isotropic, so a polar coordinate system is used to express equation (1):

$\frac{\mathrm{kt}}{\mathrm{r}} \frac{\mathrm{d}}{\mathrm{dr}}\left(\mathrm{r} \frac{\mathrm{dT}}{\mathrm{dr}}\right)+\sigma+h\left(\mathrm{~T}_{\mathrm{air}}-\mathrm{T}\right)=0$

For the horizontally placed micro heater, $\boldsymbol{h}$ is around $7.8 \mathrm{~W} / \mathrm{m}^{2} \mathrm{~K}$ [23]. Based on equation (4), a numeric method is carried out to calculate the temperature distribution for the given normalized heating power density

Table 1. Parameters for the polyimide based heater under different heating power distribution.

\begin{tabular}{|l|l|l|l|l|l|l|}
\hline $\begin{array}{l}\mathrm{k} \\
(\mathrm{W} / \mathrm{mK})\end{array}$ & $\begin{array}{l}\mathrm{t} \\
(\mathrm{m})\end{array}$ & $\begin{array}{l}\boldsymbol{h} \\
\left(\mathrm{W} / \mathrm{m}^{2} \mathrm{~K}\right)\end{array}$ & $\begin{array}{l}\mathrm{r} \\
(\mathrm{m})\end{array}$ & $\begin{array}{l}\text { Heating power } \\
\text { distribution }(1) \\
\sigma_{1}\left(\mathrm{~W} / \mathrm{m}^{2}\right)\end{array}$ & $\begin{array}{l}\text { Heating power } \\
\text { distribution }(2) \sigma_{2} \\
\left(\mathrm{~W} / \mathrm{m}^{2}\right)\end{array}$ & $\begin{array}{l}\text { Heating power } \\
\text { distribution }(3) \sigma_{3} \\
\left(\mathrm{~W} / \mathrm{m}^{2}\right)\end{array}$ \\
\hline 0.12 & $7 \times 10^{-6}$ & 7.8 & $0-0.001$ & 1000 & $\begin{array}{l}1.76 \times \\
10^{5}(0.005+\mathrm{r})\end{array}$ & $\begin{array}{l}3.75 \times \\
10^{5}(0.002+\mathrm{r})\end{array}$ \\
\cline { 4 - 7 } & & & $0.001-$ & 0 & 0 & 0 \\
\hline
\end{tabular}

In the Matlab numerical simulation, the polyimide substrate is a round plane with the radius of $2 \mathrm{~cm}$. The heating area is located in the center with a radius of $1 \mathrm{~mm}$, with a total heating power of $9.42 \mathrm{~mW}$. In the center of the heating area $(\mathrm{r}=0)$, the temperature reaches maximum or minimum while at the edge of the membrane, the temperature is set to $\mathrm{T}_{\text {air }}$ since the temperature attenuates rapidly in the non-heating area. For the calculation, we assume a different heating power distribution in the heating area shown in table 1. As with the previous result, uniform heating power density will generate a non-uniform temperature distribution [17]. To increase the uniformity of the temperature in the heating area, a different spline function is used to represent the power density for the calculation. Basically, the heating power should gradually increase from the center to the edge of the heating area. Figure (1) shows the preliminary result of how the heating power distribution affects the temperature distribution. In distribution 1, the heating area has a uniform heating power density $1000 \mathrm{~W} / \mathrm{m}^{2}$, The numerical result shows $T$ is $104^{\circ} \mathrm{C}$ at the center of 
the heater, and reduces to $50{ }^{\circ} \mathrm{C}$ at $1 \mathrm{~mm}$ from the center. In distributions (2) and (3), the heating power density linearly increases with $r$ in the scale 0 to $1 \mathrm{~mm}$. In distribution (2), heating power density goes from $880 \frac{\mathrm{W}}{\mathrm{m}^{2}}$ at the center to $1050 \frac{\mathrm{W}}{\mathrm{m}^{2}}$ at $1 \mathrm{~mm}$. While in distribution 3 , the heating power density at the center is $750 \frac{\mathrm{W}}{\mathrm{m}^{2}}$ and $1125 \frac{\mathrm{W}}{\mathrm{m}^{2}}$ at $1 \mathrm{~mm}$. From 1 to 3 , the temperature uniformity in the heating area is improved, but still not so promising.

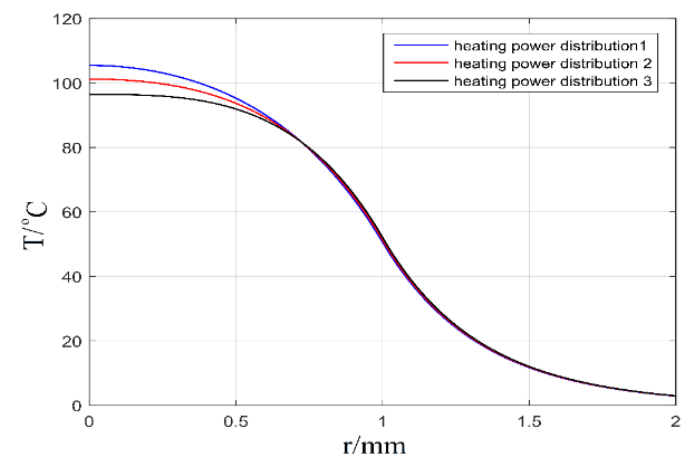

Figure 1. Temperature distribution in the membrane related to different power distribution.

Based on the theoretical equation and the numerical results of the temperature distribution in the suspended membrane, a more specific heater model is built as follows. The gold trace of the heater is a double spiral which can be simplified by a series of concentric circles. In the FEM model and the mask design, the circle is replaced by an octagon since it is much easier to design and fabricate an octagon mask, but it's performance is similar. The simplified process is shown in figure (2). The commercial software ANSYS 15 is used as the finite element modeling and simulation tool. A thermal-electric coupled field analysis is performed to observe the heat release and heat distribution on the micro-heater as current is applied.

In the FEA analysis, the thermal conductivity of the gold/titanium is also considered. The width of the space between the adjacent trace $W_{2}$ is fixed at $20 \mu \mathrm{m}$. The loading of the heating power is based on Joule's law expressed by equation (5). The width of the circle $W_{1}$ varies from the center to the edge to change the heating power density determined by equation (5), (6), (7) and (8).

$$
\begin{aligned}
& \mathrm{P}=\mathrm{I}^{2} \mathrm{R} \\
& \mathrm{R}=\rho \frac{1}{\mathrm{t}_{1} \mathrm{~W}_{1}} \\
& \mathrm{~S} \approx 1\left(\mathrm{~W}_{1}+W_{2}\right) \\
& \sigma=I^{2} \rho \frac{1}{\mathrm{t}_{1} W_{1} W^{*}}
\end{aligned}
$$

In equation (5), $P$ is the heating power, $I$ is the current, and $R$ is the resistance of each circle gold trace. Equation (6) shows the resistance $R$ is determined by several parameters: the resistivity of the gold heater $\rho$, the length of the circle $l$, the width of the circle $W_{l}$, and the thickness of the thin film $t_{l}$. The heating power density is expressed in equation (8), it's the derivative of the power over the heating area. The heating area includes the gold circle and the space between them is expressed in equation (7). $\mathrm{W}^{*}$ is roughly the sum of $W_{1}$ and $W_{2}$. Since $W_{2}$ is fixed, the only parameter that determines the power density in the heating area is $W_{1}$. By gradually reducing the width of the gold circle $W_{1}$ from the center of the heater to the edge, the power density is increased accordingly.

Table 2. The material properties of the heater in the FEA analysis.

\begin{tabular}{|l|l|l|l|l|}
\hline & $\begin{array}{l}\text { electrical resistivity } \\
(\mathbf{m} \cdot \mathbf{m})\end{array}$ & $\begin{array}{l}\text { Thermal conductivity } \\
(\mathrm{W} / \mathrm{mK})\end{array}$ & $\begin{array}{l}\text { Density } \\
\left.\frac{\mathrm{kg}}{\mathrm{m}^{3}}\right)\end{array}$ & $\begin{array}{l}\text { Specific heat } \\
\left(\frac{\mathrm{J}}{\mathrm{kg}} \times \mathrm{K}\right)\end{array}$ \\
\hline Polyimide & \multicolumn{1}{|c|}{-} & 0.12 & 1420 & 1090 \\
\hline Gold & $2.4 \times 10^{-8}$ & 314 & 19800 & 1290 \\
\hline Titanium & $4.2 \times 10^{-7}$ & 20.8 & 4506 & 540 \\
\hline
\end{tabular}



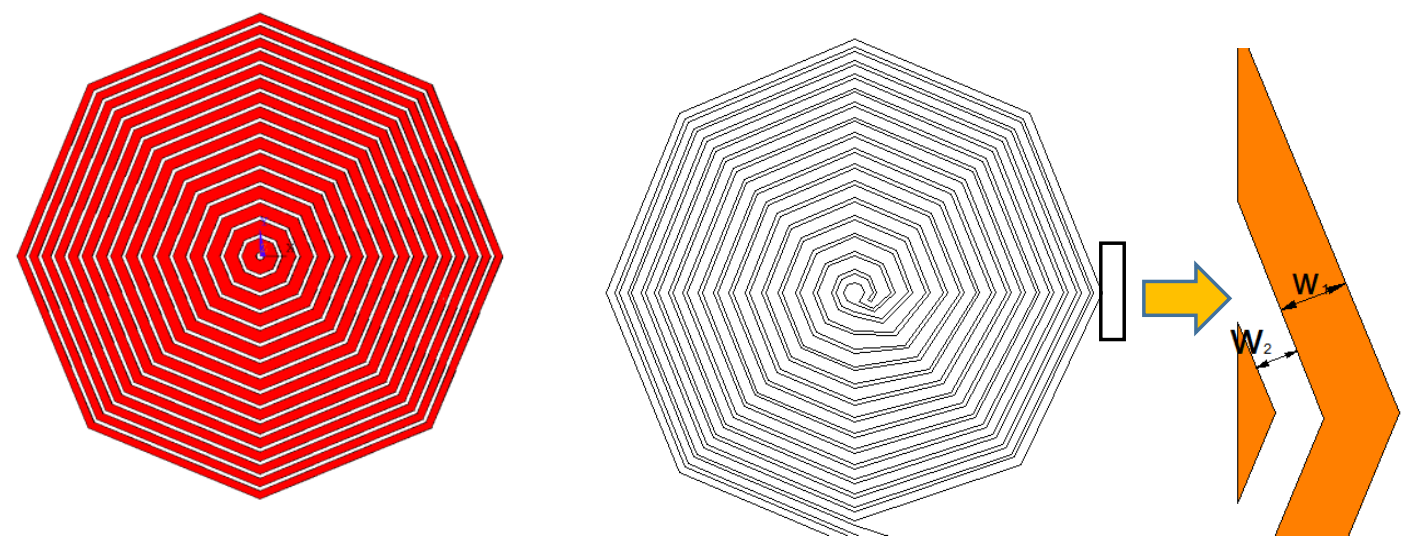

Figure 2. (a) The numerical model of the micro heater in the FEA analysis. (b) The design for the micro heater. (c) The micro structure of the heater, the width of the each circle is $W_{l}$, the space between them is $W_{2}$.

In the steady-state thermal FEA analysis the side face of the polyimide membrane is set to be the ambient temperature $\mathrm{T}_{\text {air }}$ which is $20^{\circ} \mathrm{C}$. Another equivalent boundary condition is the boundary temperature gradient is zero. This setting can be explained by the sharp temperature attenuation in the non-heating area of the membrane. The size of the polyimide membrane is $6 \times 6 \mathrm{~mm}^{2}$ while the radius for the outer circle is $1.2 \mathrm{~mm}$. A larger polyimide substrate is unnecessary since it's enough for the temperature to attenuate to ambient at $3 \mathrm{~mm}$ from the center. Solid 90 is used as the meshing element, and the free meshing method with local refinement in the heating area is used for the meshing process. Figure (3.a) shows the thermal characteristics of the polyimide heater. The total heating power is $6.28 \mathrm{~mW}$. From the simulation results, the temperature stays uniformly high in the central heating area and attenuates rapidly to the room

(a)
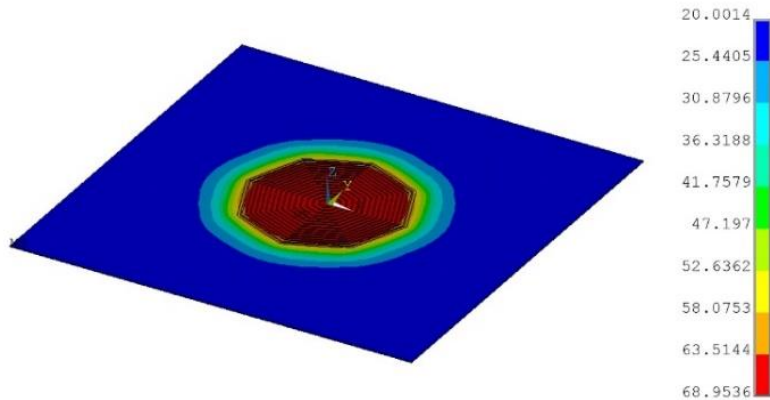

temperature in the non-heating area. For this double spiral shaped heater, how to determine the width of each circle of the heater is the key factor to reach high temperature uniformity. With the command file of ANSYS 15, it is easy to change the parameters and compare the results. The result shows how the change of the width of the circle from the center to the edge of the heater greatly affect the uniformity of the temperature which is shown in figure (3.b). From design 1 to design 3 , we try to optimize the heater to reach better temperature uniformity in the heating area by adjusting the width of each circle. In design 3 , while the average temperature is $68.7^{\circ} \mathrm{C}$, the largest temperature difference is less than $0.3{ }^{\circ} \mathrm{C}$ in the area where the radius is less than $1 \mathrm{~mm}$. Considering the radius of the whole heating area is $1.2 \mathrm{~mm}$, this result is quite satisfying.

(b)

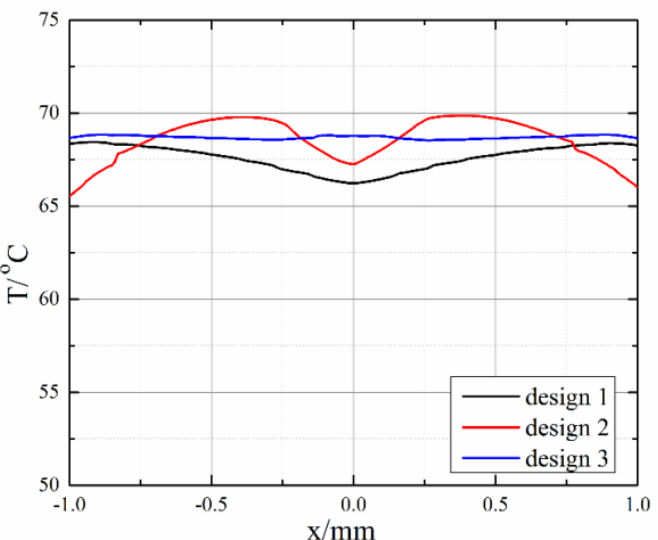


Figure 3. (a) The temperature distribution in the polyimide membrane by FEA simulation. (b) Temperature distribution along the diameter of the heater for different heater design.

\subsection{Fabrication process}

The fabrication starts with the preparation of the silicon chip, which is then cleaned by acetone, IPA, and water in an ultrasonic cleaner. After cleaning, the silicon wafer is baked on a hotplate with surface temperature of $160^{\circ} \mathrm{C}$ for fully drying. Liquid polyimide PI2611 is used to fabricate the flexible polyimide substrate with a thickness of $7 \mu \mathrm{m}$. After thawing at room temperature for $30 \mathrm{~min}$, the liquid polyimide sample is then put in a vacuum chamber for degassing [24]. After degassing, the liquid polyimide is spin-coated on the silicon carrier. After the spin-coating, the thin film sample is soft-baked on the hotplate under $100^{\circ} \mathrm{C}$ for 2 min and then the baking temperature is slowly ramped to 350 ${ }^{\circ} \mathrm{C}$ in about 2 hours. After fully cured, the sample is gradually cooled down to the room temperature and then removed from the hotplate. After the patterning of the positive photoresist on the polyimide substrate by photolithography, a $10 \mathrm{~nm}$ layer of titanium is deposited on the polyimide substrate as an adhesive layer and then followed by the deposition of a $100 \mathrm{~nm}$

a. Silicon wafer cleaning

b. Polyimide spin coating and curing

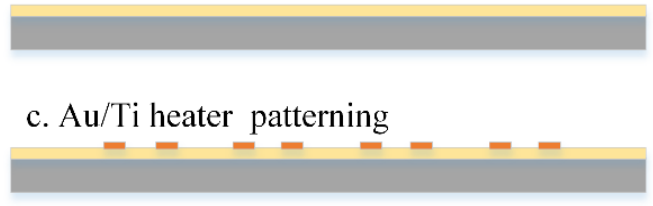

d. Device packaged by polyimide

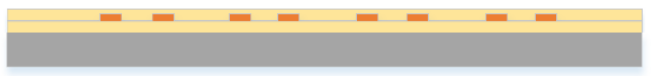

e. Device peeled off from the wafer

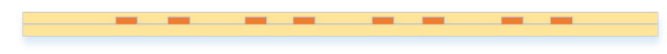

(a)

Figure 4. (a) The fabrication process of the micro heater. (b) The peeled off micro heater array. peeled off heater array. step.

(b) layer of gold by e-beam deposition. After a 2 hours lift off, the gold heater is patterned on the polyimide substrate. After being coated with another protective polyimide layer, the sample is then peeled off from the silicon carrier easily. Figure (4.a) shows the fabrication process and Figure (4.b) shows the sample of the

Conventionally, people use commercial polyimide as the substrate by attaching the polyimide membrane onto the silicon wafer with some adhesion layer [25], or using relatively thick PI substrate $(100 \mu \mathrm{m})$ without silicon carrier [26]. However, ultrathin polyimide is needed to reach high thermal isolation. For a polyimide thin film less than $10 \mu \mathrm{m}$ thick, it would be difficult to mount on the silicon wafer without leaving any bubbles inside. Besides, the introduction of the adhesion layer would also cause difficulty for the separation of the polyimide thin film and the silicon carrier in the later

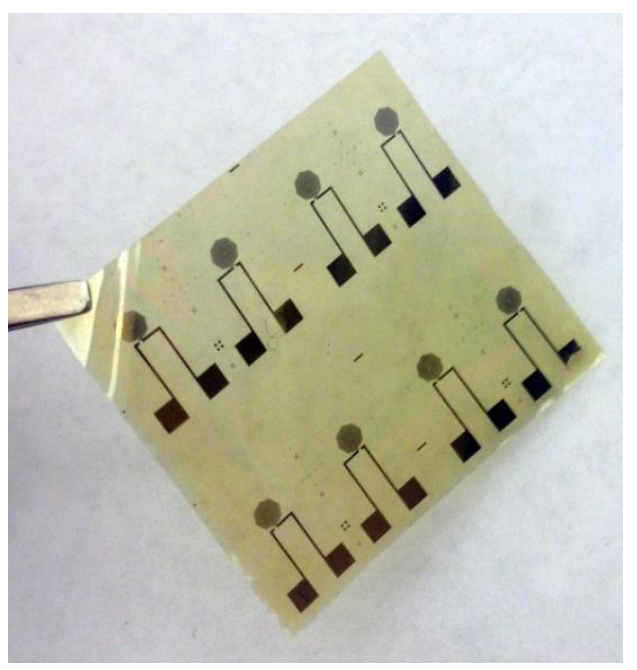

\section{Test Result}

\subsection{Heater Characterization}

The characterization of the gold heater is carried out in the chamber of a high temperature probe station (AO 600 Compact Rapid Thermal Annealing System, MBE). A small constant current $(10 \mu \mathrm{A})$ is added to the heater to measure its resistance at different setting temperature in the chamber. The high temperature probe station is integrated with a test chamber with: excellent thermal isolation, a PID temperature controller, a quartz beam heater, and an I/O system, as shown in figure (5). The resistance of the gold heater and the ambient temperature share a linear relationship and is expressed in equation (8). 


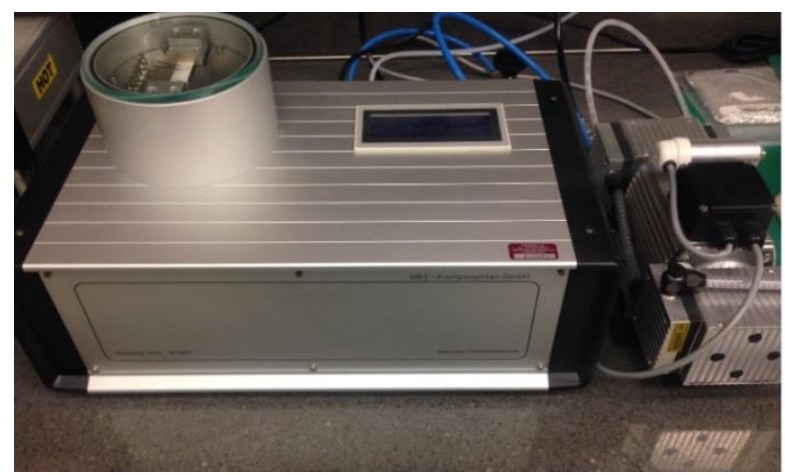

Figure 5. High temperature probe station for the characterization.

$\mathrm{R}=\mathrm{R}_{0}+\alpha \mathrm{R}_{0}\left(\mathrm{~T}-\mathrm{T}_{0}\right)$

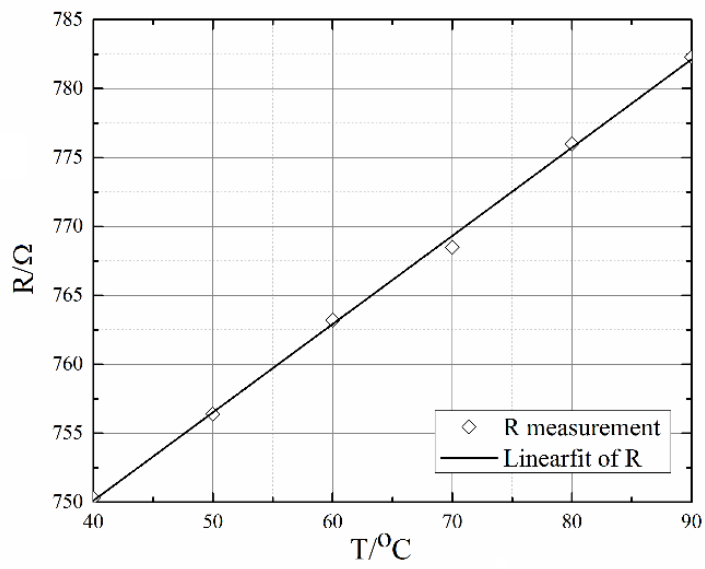

Figure 6. R-T characterization of the micro heater
Figure (6) shows the characterization of the temperature coefficient of the resistance for the gold heater which is treated several times in an annealing process. In the measurement range, the resistance changes linearly with the rise of temperature. The temperature coefficient of gold is $0.09 \%$ in the temperature range of $40{ }^{\circ} \mathrm{C}$ to $90{ }^{\circ} \mathrm{C}$ which is significantly smaller than that of the bulk gold which is possibly due to the porosity of the evaporated thin film $[27,28]$.

\subsection{Temperature Measurement}

A sophisticated feedback control system was applied to achieve programmable constant power supply for the heater. A thermal image camera was used to measure the temperature distribution of the heater as shown in figures (7.a, 7.b). The temperature of thousands of points was measured by the camera and each were used to draw the map of the temperature distribution. Figure (7.c) shows the temperature of the heating area has about $0.45^{\circ} \mathrm{C}$ in variance and $53.7^{\circ} \mathrm{C}$ average when $6.28 \mathrm{~mW}$ heating power was loaded. The average temperature is significantly smaller than the simulation result $\left(53.7^{\circ} \mathrm{C}\right.$ compared to $68.7^{\circ} \mathrm{C}$ ) which may be caused by the difference between the real heat convection coefficient and the input simulation parameter. The value of convection coefficient is greatly affected by the forced convection and will increase when the temperature of the heating area increases [29]. The temperature variance is consistent with the simulation result and is much smaller than the previous

result

[20]. a

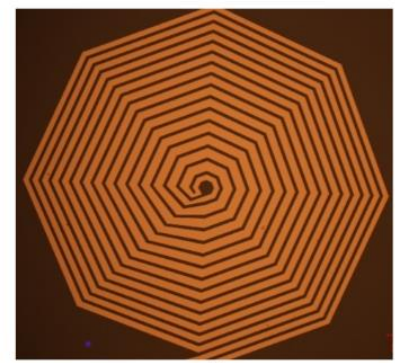

b

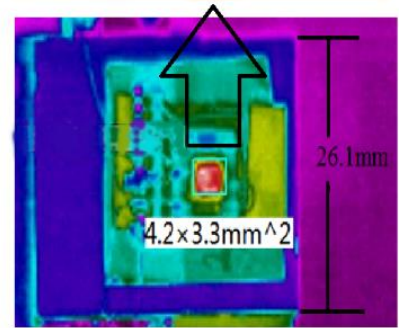

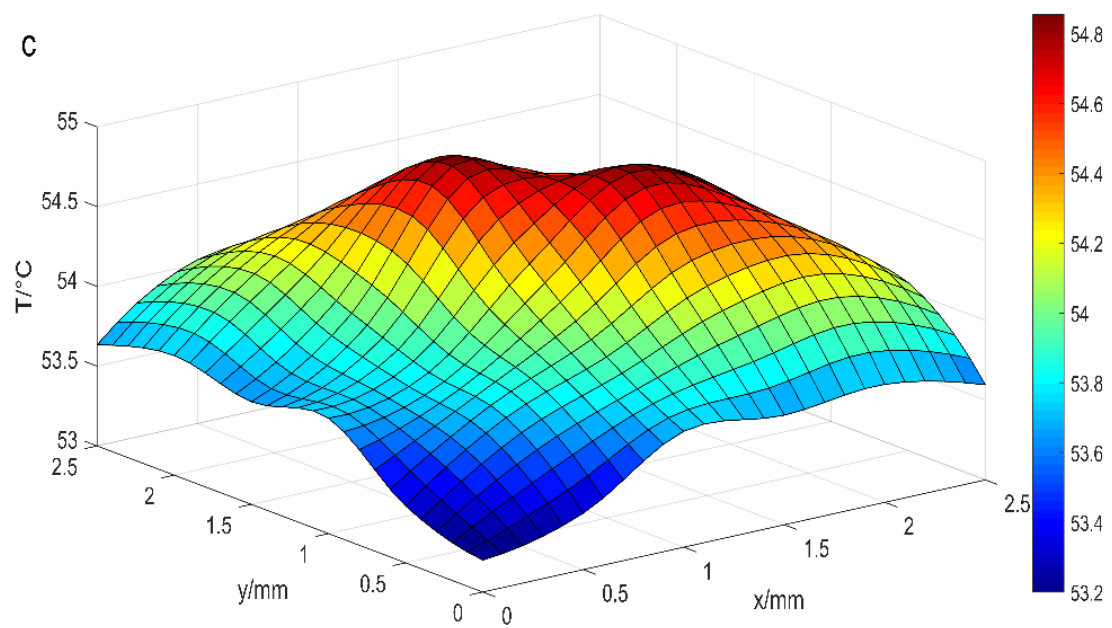

C

Figure 7. (a) The gold heater image under the microscope. (b) The IR image of the gold heater under $6.28 \mathrm{~mW}$ heating power. (c) The Temperature distribution in the heating area measured by the IR camera. 


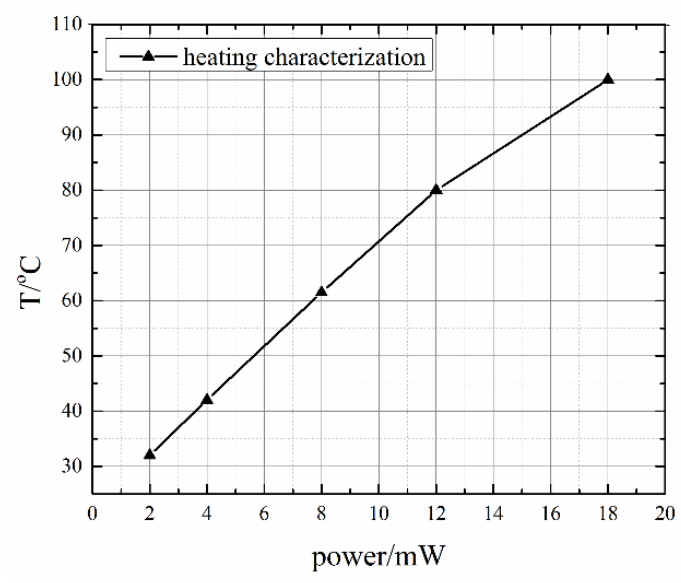

Figure 8 . The measured heater temperature under different heating power consumption in atmosphere

Figure (8) shows the temperature of the heating area as a function of the supplied power. The temperature increase rate is $5.6^{\circ} \mathrm{C} / \mathrm{mW}$ when temperature of the heating area is below $100^{\circ} \mathrm{C}$. This rate indicates the amount of heat loss which is related to the thermal isolation of the heater. The temperature increase rate could be larger if the chamber is under vacuum.

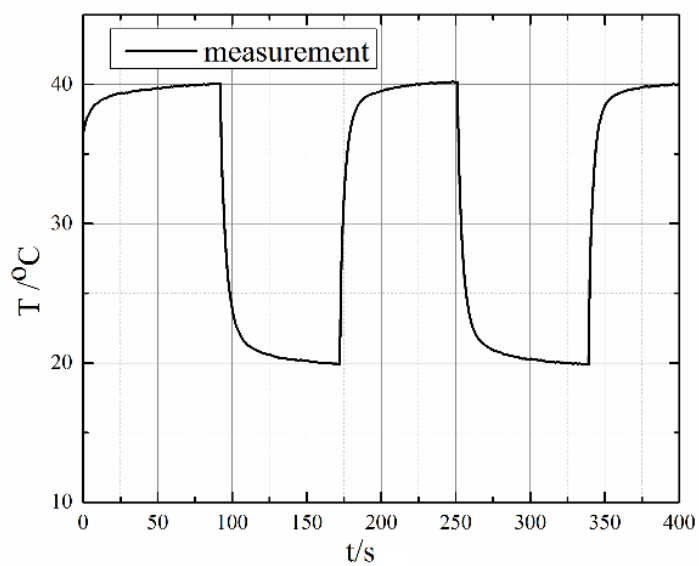

Figure 9. The step response of $8 \mathrm{~mW}$ heating power for the micro heater when there is $2 \mu \mathrm{L}$ water on the top.

The micro heater could be used for various types of heating processes. The response time is determined by the thermal mass of the load $\mathrm{C}$ and the equivalent heat conduction coefficient $\mathrm{G}$. The device could be regarded References[1] Yin, J., Yu, S., Wang, S., Lu, M., \& Zuo, L. (2014, August). Design and Fabrication of Flexible Differential Scanning Nanocalorimeter. In ASME 2014 International Design Engineering Technical Conferences and Computers and Information in Engineering Conference (pp. as a $1^{\text {st }}$ order linear system [30] which can be expressed by equation (9).

$C \frac{d T}{d t}+G\left(T-T_{\text {air }}\right)=P$

Figure (9) shows when there is $2 \mu \mathrm{L}$ liquid water loaded on the micro heater, the average temperature could rise up by $20^{\circ} \mathrm{C}$ under $8 \mathrm{~mW}$ heating power. The time constant for this first order heating system is $4.3 \mathrm{~s}$.

\section{Conclusion}

We have designed and fabricated a novel gold heater on a polyimide substrate with high temperature uniformity in the heating area and short response time. The double spiral heater is a series of concentric octagons. By FEA simulation and optimization, the heater achieves high temperature uniformity in the heating area which makes it possible for use in the application of gas and other types of sensors. The temperature variance is only $0.45^{\circ} \mathrm{C}$ when the heating area reaches $53.7^{\circ} \mathrm{C}$ in average with $6.28 \mathrm{~mW}$ power supply. By introducing the polyimide as the substrate, the micro heater has high thermal insulation, the power consumption is relatively low to drive the heater to a certain temperature with heating coefficient $5.6^{\circ} \mathrm{C} / \mathrm{mW}$. The step response time for $2 \mu \mathrm{L}$ water droplet is only $4.3 \mathrm{~s}$, shows its potential in the application in calorimetry and micro actuators.

\section{Acknowledgement}

The authors thank the funding support from NSF (IDBR \#1530508) and AbbVie Inc. The fabrication was carried out at the Center for Functional Nanomaterials (CFN) of Brookhaven National Laboratory, which is supported by the U.S. Department of Energy, Office of Basic Energy Sciences, under Contract No. DE-AC02-98CH10886. We also thank Dr. Fernando Camino for his help with the test platform settlement and Mr. Jackson A. Klein for his work with the English editing.

V004T09A002-V004T09A002). American Society of Mechanical Engineers.

[2] Mo, Y., Okawa, Y., Tajima, M., Nakai, T., Yoshiike, N., \& Natukawa, K. (2001). Micromachined gas sensor array based on metal film micro-heater. Sensors and Actuators B: Chemical, 79(2), 175-181. 
[3] Van Herwaarden, A. W., Sarro, P. M., Gardner, J. W., \& Bataillard, P. (1994). Liquid and gas microcalorimeters for (bio) chemical measurements. Sensors and Actuators A: Physical, 43(1), 24-30.

[4] Fürjes, P., Dücső, C., Ádám, M., Zettner, J., \& Bársony, I. (2004). Thermal characterisation of micro-hotplates used in sensor structures. Superlattices and Microstructures, 35(3), 455-464.

[5] Wu, S., Lin, Q., Yuen, Y., \& Tai, Y. C. (2001). MEMS flow sensors for nano-fluidic applications. Sensors and Actuators A: Physical, 89(1), 152-158.

[6] Noh, S., Seo, J., \& Lee, E. (2009). The fabrication by using surface MEMS of $3 \mathrm{C}-\mathrm{SiC}$ micro-heaters and RTD sensors and their resultant properties. Trans. Electr. Electron. Mater, 10, 131-134.

[7] Creemer, J. F., Briand, D., Zandbergen, H. W., Van der Vlist, W., de Boer, C. R., de Rooij, N. F., \& Sarro, P. M. (2008). Microhotplates with TiN heaters.Sensors and Actuators A: Physical, 148(2), 416-421.

[8] Briand, D., Colin, S., Gangadharaiah, A., Vela, E., Dubois, P., Thiery, L., \& De Rooij, N. F. (2006). Micro-hotplates on polyimide for sensors and actuators.Sensors and Actuators A: Physical, 132(1), 317-324.

[9] Huber, D. L., Manginell, R. P., Samara, M. A., Kim, B. I., \& Bunker, B. C. (2003). Programmed adsorption and release of proteins in a microfluidic device.Science, 301(5631), 352-354.

[10] Sökmen, Ü., Stranz, A., Fündling, S., Wehmann, H. H., Bandalo, V., Bora, A., ... \& Peiner, E. (2009). Capabilities of ICP-RIE cryogenic dry etching of silicon: review of exemplary microstructures. Journal of Micromechanics and Microengineering, 19(10), 105005.

[11] Puigcorbe, J., Vogel, D., Michel, B., Vila, A., Gracia, I., Cane, C., \& Morante, J. R. (2003). Thermal and mechanical analysis of micromachined gas sensors. Journal of Micromechanics and Microengineering, 13(5), 548.

[12] Zhang, J., Zhang, R., Wang, X., Feng, W., Hu, P., O'Neill, W., \& Wang, Z. (2013). Fabrication of highly oriented reduced graphene oxide microbelts array for massive production of sensitive ammonia gas sensors. Journal of Micromechanics and Microengineering, 23(9), 095031.

[13] Teyssieux, D., Briand, D., Charnay, J., de Rooij, N. F., \& Cretin, B. (2008). Dynamic and static thermal study of micromachined heaters: the advantages of visible and near-infrared thermography compared to classical methods.Journal of Micromechanics and Microengineering, 18(6), 065005.
[14] Aslam, M., Gregory, C., \& Hatfield, J. V. (2004). Polyimide membrane for micro-heated gas sensor array. Sensors and Actuators B: Chemical, 103(1), 153-157.

[15] Metz, S., Holzer, R., \& Renaud, P. (2001). Polyimide-based microfluidic devices. Lab on a Chip, 1(1), 29-34.

[16] Langereis, S., Keupp, J., van Velthoven, J. L., de Roos, I. H., Burdinski, D., Pikkemaat, J. A., \& Grüll, H. (2009). A temperature-sensitive liposomal $\mathrm{H}$ CEST and $19 \mathrm{~F}$ contrast agent for MR image-guided drug delivery. Journal of the American Chemical Society, 131(4), 1380-1381.

[17] Cozzani, E., Summonte, C., Belsito, L., Cardinali, G. C., \& Roncaglia, A. (2007, October). Design study of micromachined thermal emitters for NDIR gas sensing in the 9-12 $\mu \mathrm{m}$ wavelength range. In Sensors, 2007 IEEE (pp. 181-184). IEEE.

[18] Wang,S., Yu,S., Ihnat,P., Filoti,D., Lu,M.,\&Zuo, L. (2016). Micro-differential scanning calorimeter for liquid biological samples. Journal of Micromechanics and Microengineering. (In publication)

[19] Simon, I., Bârsan, N., Bauer, M., \& Weimar, U. (2001). Micromachined metal oxide gas sensors: opportunities to improve sensor performance. Sensors and Actuators B: Chemical, 73(1), 1-26.

[20] Cess, R. D. (1964). The interaction of thermal radiation with conduction and convection heat transfer. Advances in Heat Transfer, 1(1).

[21] Batchelor, G. K. (1954). Heat convection and buoyancy effects in fluids.Quarterly Journal of the Royal Meteorological Society, 80(345), 339-358.

[22] Widder, D. V. (1976). The heat equation (Vol. 67). Academic Press.

[23] Awbi, H. B. (1998). Calculation of convective heat transfer coefficients of room surfaces for natural convection. Energy and Buildings, 28(2), 219-227.

[24] Stead, D. A., Reid, R. G., \& Taylor, R. B. (1998). Capillary electrochromatography of steroids: Increased sensitivity by on-line concentration and comparison with high-performance liquid chromatography.Journal of Chromatography A, 798(1), 259-267

[25] Jia, Y., Wang, B., Zhang, Z., \& Lin, Q. (2014). A polymer-based MEMS differential scanning calorimeter. Sensors and Actuators A: Physical.

[26] Moschou, D., Vourdas, N., Kokkoris, G., Papadakis, G., Parthenios, J., Chatzandroulis, S., \& Tserepi, A. (2014). All-plastic, low-power, disposable, continuous-flow PCR chip with integrated microheaters for rapid DNA amplification. Sensors and Actuators B: Chemical, 199, 470-478. 
[27] Westwood, W. D. (1974). Porosity in sputtered platinum films. Journal of Vacuum Science \& Technology, 11(1), 466-471.

[28] Lopeandia, A. F., Rodríguez-Viejo, J., Chacón, M., Clavaguera-Mora, M. T., \& Muñoz, F. J. (2006). Heat transfer in symmetric U-shaped microreactors for thin film calorimetry. Journal of Micromechanics and Microengineering, 16(5), 965.

[29] Welty, J. R., Wicks, C. E., Rorrer, G., \& Wilson, R. E. (2009). Fundamentals of momentum, heat, and mass transfer. John Wiley \& Sons.

[30] Garden, J. L., \& Bourgeois, O. (2012). Nanocalorimetry. Encyclopedia of nanotechnolgy, 1491-1504. 


\section{Biographies}

Shifeng $\mathbf{Y u}$ is currently a $\mathrm{PhD}$ candidate in Virginia Tech. He got his bachelor degree in the University of Science and Technology of China in the department of mechanical engineering. He then went to Stony Brook University to pursue a $\mathrm{PhD}$ degree in mechanical engineering and later transferred to Virginia Tech. His research interests include nanofabrication, MEMS based sensor and actuator, bio calorimetry.

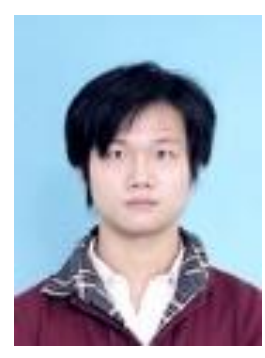

Shuyu Wang is currently a $\mathrm{PhD}$ candidate in Stony Brook University. He got his bachelor degree in the Huazhong University of Science and Technology in the

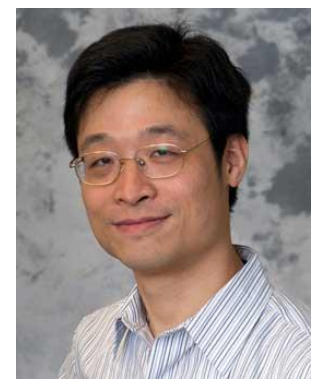
department of mechanical engineering. He is currently a third year $\mathrm{PhD}$ student in the mechanical engineering in Stony Brook University. His research interests include

nanomaterials, MEMS sensors and calorimetry.

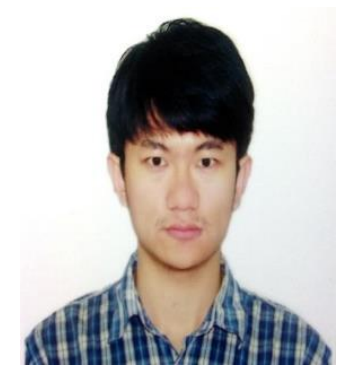

Lei Zuo is an associate professor in the department of mechanic engineering in Virginia Tech. He got the bachelor degree from Tsinghua University and got the master degree together with the $\mathrm{PhD}$ in MIT. His research interests include thermoelectric materials and applications, bio sensors and instrumentation, large-scale energy harvesting from ocean waves, vehicle suspensions, civil structure vibration, railroad transportation, etc.

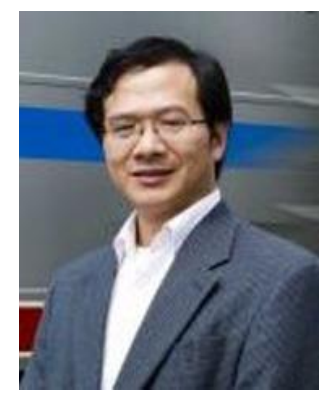

Ming Lu is a stuff scientist in the center of functional nanomaterials in Brookhaven National Lab. He got the bachelor degree in Fudan University, China and PhD in the department of physics and astronomy in Stony Brook University. His research focuses on the exploration of new methods and new materials for nanofabrication, especially for photonics and x-ray microscopy applications. 